CESIS Electronic Working Paper Series

Paper No. 388

Residential energy consumption and conservation

\author{
Björn Hårsman \\ Marie H. Wahlström
}

December, 2014

The Royal Institute of technology

Centre of Excellence for Science and Innovation Studies (CESIS)

http://www.cesis.se 


\title{
Residential energy consumption and conservation
}

\author{
Björn Hårsman ${ }^{1}$ \& Marie H. Wahlström ${ }^{2}$
}

\begin{abstract}
The Swedish energy performance certificates for single family housing provide rich information on energy consumption and various physical attributes. They also include estimates of the energy conservation potentials resulting from implementing cost-efficient energy saving measures. By matching the certificates issued for single family houses in 2009 and 2010, with data from other sources we have created a unique data-base which can be used to explore a wide variety of questions related to energy consumption and conservation.

One aim of this paper is to assess the role for energy consumption played by socio-economic characteristics of the residents as compared to physical attributes of the house. Another is to estimate the influence of housing attributes and climate on the "engineering estimates" of the conservation potentials and analyze to what extent the two estimated relationships are consistent.
\end{abstract}

Our results show that while the quantitative impact of physical attributes dominate the energy use for heating and cooling, the opposite holds for the consumption of household electricity. The assessed conservation potential, amounting to 15 percent of the energy consumption, is significantly related to both the housing attributes and the energy consumption. The results also indicate a need to improve the information provided by the performance certificates.

JEL codes: D12, Q 28, R31

Keywords: Energy consumption, Energy conservation, Single family housing, Energy performance certificates, Household characteristics

\footnotetext{
${ }^{1}$ Department of Industrial economics and Management, Royal Institute of Technology. E-mail: bjorn.harsman@indek.kth.se

${ }^{2}$ Department of Urban Planning and Environment, Royal Institute of Technology. E-mail: mia.wahlstrom@abe.kth.se
} 


\section{Introduction}

As one of several steps taken to reduce the use of energy and the emission of climate gases, Sweden adopted a law on energy performance certification of buildings in 2006. The law, which is based upon European Union directives, prescribes that rental buildings, cooperative buildings and some non-residential buildings must have energy performance certificates issued by approved experts from 2009. Single-family housing owners are obliged to have the prescribed certificate no later than at the time of selling the house. If the seller does not present such a certificate before the contract of sale is signed the buyer has the right to carry out a certification at the seller's expense.

The idea behind the performance certificates is of course that the information about energy usage, energy-related physical attributes and expert advice on energy conservation should make the households more aware of their energy consumption and, hopefully, take measures to reduce it. Since the residential sector accounts for such a large fraction of the overall final energy use - 21 percent in Sweden and 26 percent for 27 EU-countries according to Mata et al [18] - it seems clear that even small reductions would be useful.

Several studies support the idea that consumers should benefit from better information. Using survey data from the UK, Mansouri et al [17] concludes that households are interested in receiving information concerning their energy use and the associated environmental impact as well as in modifying their behavior. Analyzing data from two large-scale field experiments Ayres et al [1] concludes that the 75000 participating household customers of two US utilities tend to make substantial and lasting energy savings when receiving reports comparing their energy consumption with neighbors in similar houses. The system of housing certificates might give rise to similar effects provided that the involved households make rational use of the information obtained, by e $\mathrm{g}$ implementing the cost-efficient saving measures suggested by the experts. However, it should be kept in mind that a large fraction of the households do in fact make irrational choices when faced with different alternatives for reducing their use of energy, see Brounen et al [4].

The information provided by the energy performance certificates for single family houses issued in Sweden 2009 and 2010 constitute the main source of data for this paper. By complementing this information with data from other sources, the certificates can be used to deepen the current knowledge about the quantitative impact of housing attributes, household 
characteristics and climate on the energy consumption as well as the assessed conservation potential. The data can also be used to explore to what extent the expert estimates of the conservation potential and the observed energy usage are related to the same explanatory variables. These are the basic aims of our paper and we will use regression analysis to address and analyze the following questions.

- How do the energy conservation potentials suggested by the experts depend upon the physical attributes of the houses evaluated, upon the current energy use and the local climate?

- What role do different household characteristics and indicators of their environmental awareness play for the energy consumption as compared with the energy related attributes of the house and the climate?

- To what extent are the experts' energy conservation assessments consistent with the estimated relationship between energy use and different explanatory factors?

Our third question relates to a much wider one about the quality of expert assessments. Though not a main aim of this paper, the indicated regressions will shed light on some quality-related aspects and we will touch upon others when presenting our data.

In line with earlier studies our results show that the energy consumption not only depends on housing attributes such as vintage and type of heating system but also on socio-economic characteristics of the residents, see for example Guerra Santin et al [9], Kelly [15] and Brounen et al [3]. By way of example the total energy use in a house constructed 1921-1940 is 23 percent higher than in a house constructed after 2000 and it will increase with 2,7 percent with one additional resident. The average of the estimated conservation potentials, all of which are based on cost-efficient saving measures, is 3,575 $\mathrm{kWh}$ per house, which amounts to 15 percent of the average total energy consumption per house. The conservation potentials are strongly related to the energy use - an increase of the total energy consumption by 10 percent increases the corresponding conservation estimate by 16 percent.

Our paper provides new knowledge on the conservation estimates provided by the experts responsible for the energy performance certificates and also on the consistency between these estimates and the observed energy consumption. The large and in many respects unique data base is also a new contribution to the earlier literature in this field of research 
Another reason making this study interesting outside Sweden is that most EU-countries have similar energy performance certificates for housing. Since Sweden has a relatively long tradition of an ambitious environmental policy one would expect a fairly high degree of environmental awareness among Swedish consumers. It might hence be especially interesting to use Sweden as a benchmark when analyzing certificates from other countries.

The rest of our paper is organized as follows. The next section provides an overview of previous research and a presentation of hypothesis related to our research questions. Section three describes the data and section four the estimations. A short summary and some conclusions for policy and future research are presented in the final section.

\section{Literature overview}

As described by Swan and Ugursal [20], the frameworks commonly used to analyze residential energy consumption can be grouped into top-down and bottom-up approaches. The top-down approaches, which will not be dealt with further here, are based on an aggregated view and usually relate the energy consumption of the residential sector to factors such as for example gross domestic product, fuel prices, new construction and demolition of housing and to climate conditions. The bottom-up methods treat housing in a disaggregated way and make it possible to analyze the energy consumption impact of different housing attributes as well as of household characteristics and occupant behavior.

The bottom-up approaches can, as also suggested by Swan and Ugursal [20] be further divided into those based on building physics or engineering methods and those based on statistical techniques. Though this paper applies statistical methods, we will also review some papers of the engineering kind since they usually tend to have a richer representation of housing attributes related to the energy performance.

\subsection{Engineering methods}

According to Kavgic et al [14], the characteristic feature of engineering models is the use of heat balance equations to calculate the energy consumption of different types of dwellings representing the entire stock of housing. The dwelling types are classified in terms of 
attributes such as type of housing (i.e. detached single family house), period of construction, attributes characterizing the heating system, the area of different housing elements (i.e. the floor and the windows) along with their thermal characteristics. There are both simpler models used for estimating the demand for space heating and more elaborated ones handling all end uses within the dwelling. Broin et al [2], Caldera et al [5] and Haas et al [12] provide examples of models focused on the energy use for space heating and cooling.

By including survey data on the average use of appliances, lightening, water heaters and indoor air temperature, engineering models can also be used to estimate the end-use of energy for different purposes. Mata et al [18] describes and makes use of such a model to assess the potential for improving the energy performance of the Swedish residential sector. This is done by modeling the impact of energy saving measures such as improved thermal performance of the building envelope, lower indoor air temperature and reduction of power for lightening and appliances, and the authors conclude that the final energy demand of the Swedish housing stock can be reduced by over 50 percent by applying this kind of measures. Larsen and Nesbakken [16] suggests that engineering models using survey information on the average use of e g lightening and appliances can be improved if the surveys are designed for analyzing the end-use econometrically.

As pointed out by e g Swan and Ugursal [20] a main advantage of the engineering models is their detailed treatment of dwelling and building attributes and the possibility to evaluate the impact of new technology. The most important drawback is the simplified treatment of the households giving rise to the demand modeled.

\subsection{Statistical methods}

Guerra Santin et al [9] states that the better the thermal properties and installations of buildings become, the stronger the need will be to consider the role household characteristics and household behavior play for the consumption of energy. Whether the need is becoming stronger or not, the number of studies addressing that role has certainly increased during the last decade.

Guerra Santin et al [9] uses data from a sample of 15000 dwellings in the Netherlands to quantify the impact of housing attributes, household characteristics and occupant behavior on 
the use of energy for space heating. By applying analyses of variance, the study concludes that building characteristics "explain" ten times more of the energy use for heating as compared to occupant characteristics and behavior (42 versus 4,2 percent). Household size, income and age has a significant and positive impact on the energy use and, as expected, more energy is needed the larger the useful living area and the older the dwelling. Type of building, insulation of different parts of the building envelope and presence of bath are examples of other factors shown to have significant impact. Their results also indicate a co-variation between some housing attributes and occupant behavior, defined in terms of using the ventilation and heating system and daytime presence in the home. Considering this, the authors suggest that the influence of occupant characteristics might be underestimated.

Another study [10] looks closer at the effects of occupants' behavior using self-reported data from a Dutch household survey. Though the response rate is only five percent the results indicate that the type of heating and ventilation system influence the behavior and that households having a programmable thermostat tends to turn their radiators on for longer periods than households with manual thermostats. In a follow-up study based on the same data, Guerra Santin [11] elaborates on the relationship between behavior - defined as daily use of space, heating systems and other amenities - and energy consumption for space and water heating. Though no statistically significant differences regarding energy use was found between the defined "user profiles", the author concludes that the results indicate a need to look closer into the causes behind behavior.

Brounen et al. [3] is another study of residential energy use in the Netherlands. They use data for more than 300000 households and analyze, to what extent the consumption of gas and electricity can be related to different building and dwelling attributes as compared to characteristics of the households. Unlike Guerra Santin et al [9], they control for climate differences across the Dutch provinces. Their results indicate that residential gas consumption, which is used for heating, is determined principally by structural dwelling attributes such as e g type and vintage of the building, while electricity consumption varies more directly with household characteristics, in particular income and family composition. It is for example shown that families with children consume significantly more electricity than those without children and that this effect is stronger the older the children. The results for gas consumption are in line with those reported by Guerra Santin et al [9] concerning the 
dominance of housing attributes over occupant characteristics as explanatory factors and the strong impact of dwelling size.

According to, Costa and Kahn [7] the current use of residential energy may also be affected by earlier adopted habits. Using Census data providing data on the electricity consumption of California homes of different vintages, they analyze how the electricity price, at the time when a home was built, influences its later observed electricity consumption. They conclude that low electricity prices at the time of construction are an important determinant of a home's electricity consumption, even several years later on and that the opposite also holds. Their study confirms the strong impact of housing vintage on energy consumption.

Kelly [15] explores factors influencing the energy expenditure among a sample of around 2500 British households and finds that family size and income as well as floor area all have a significant and positive impact. The energy expenditure is also positively related to the difference between outdoor and indoor temperature and to the time different rooms are heated during weekends and daytime. More unexpectedly, the study also finds that only a small proportion of the variance in energy consumption between the households can be related to the energy performance of their homes. As pointed out by the author this might indicate a rebound effect, implying that a proportion of the energy saved by an energy efficient house is "taken back" to increase the indoor temperature or other kinds of additional energy consumption.

Several studies do also indicate the importance of considering environmental attitudes. Mansouri et al [17] elucidates the link between household energy consumption and environmental attitudes among a sample of UK households and relates ownership and usagepatterns of domestic appliances to stated reasons for energy-thrift. Their analysis shows that environmental concerns influence the saving decisions but also that needs for improving comfort and reducing energy bills often are considered even more important. This priority seems to be supported by an analysis of the willingness of Slovenian households to pay for green electricity, see Zoric and Hrovatin [21]. They conclude that while environmental awareness plays an important role for attitudes to green electricity, the willingness to pay for it mainly depends on household income. Another study of the stated preferences type among Swedish households, Ek and Söderholm [8] lends support to this conclusion and finds that 
social interaction is an additional factor that should be considered when analyzing household electricity saving behavior ${ }^{3}$.

Sexton and Sexton [19] develop a theory of conspicuous conservation, aiming at explaining the behavior of individuals seeking status through displays of environmental concern and commitment. Their results suggest that people have different reasons for living or acting "green"; some motives are more related to image while others are more related to sincere or intrinsic intentions regardless of the outcome (so called Bona Fides).

\footnotetext{
${ }^{3}$ Social interaction is measured by the respondents' answers to questions about how often they discuss electricity usage and savings with close people and if they believe that other families in the municipality are reducing their energy 'consumption.
} 


\subsection{Hypotheses}

Based on the reviewed studies, we will use our data on single family housing in Sweden to test the following hypotheses relating the energy use to housing attributes and household characteristics.

Housing attributes: The energy consumption increases with the size and age of the house, the simpler the windows and the lower the outdoor temperature. It is lower for detached than for semi-detached and duplex dwellings and if it has recently got a new roof or façade. We also expect that the energy consumption will be lower in houses equipped with any kind of heat pump.

Household characteristics: The energy consumption increases with family size and income and is lower among older, higher educated and "greener" householders.

We will use both the total energy consumption, the energy consumption for heating-cooling and the consumption of household electricity as dependent variables in our regressions. The reason is that we also want to test the hypothesis that housing attributes dominate over household characteristics as explanatory factors for heating and cooling while the contrary holds for household electricity.

As far as we know, there are no other studies providing guidance for hypotheses concerning expert conservation assessments of the kind available in our database. Assuming that the experts use all information considered relevant when inspecting a house, we will test if the assessed savings are larger the higher the observed energy consumption and if the impact of the housing attributes corresponds to their hypothesized impact on the energy consumption.

\section{The Data}

The data set is based upon the energy certificates for all Swedish single-family houses sold in 2009 and 2010 and issued by experts approved by the Swedish National Board of Housing, Building and Planning. The certificates provide detailed information about the energy consumption and the type of energy and heating system used and also about building attributes such as type of house and year of construction [22]. The energy consumption is 
expressed in kilowatt- hours $(\mathrm{kWh})$ during the preceding twelve month, for heating/cooling and as well as for other purposes. The transformation to $\mathrm{kWh}$ for other types of energy than electricity is made by the certification experts using conversion factors provided by the Swedish Energy Agency. In some cases, e g when electricity is the only source of energy, the total consumption of energy is measured and the use for different purposes is estimated by the experts and in others, e $\mathrm{g}$ for houses having oil-boiled heaters, both the consumption of oil and of electricity is measured. Since the climate may vary considerably from year to year, the experts also provide the energy consumption data transformed to a year considered to be normal from a climate point of view.

Additionally, the certificates include expert estimates of conservation potentials and the corresponding annual cost per $\mathrm{kWh}$ saved. All saving measures suggested, ranging from strip seals for windows to installations of heat pumps, should be cost-efficient implying that the annual cost of a measure during its economic life time should be lower than the variable energy cost. The assessed energy savings and costs are included in our data base but no other information about the underlying measures

The certification data has been matched with three other sets of data by the Swedish Central Bureau of Statistics. One is based upon the real estate tax assessments and provides data on transaction prices and additional information about the housing attributes. The other two provide socio-economic characteristics of the (selling) households and various attributes of the neighborhood (municipality and parish) where a house is located.

The quality of the information provided by the certificates has not, unlike the data from the other three sources, been examined by the responsible government agency. In order to improve the quality of the matched data base we have therefore excluded certificates with inconsistent information. For example, houses reported to have an unrealistically large floor area compared to the plot size are excluded like those for which the suggested energy saving exceeds the reported energy consumption. Houses with a reported energy use equal to zero or having a household electricity consumption exceeding the energy use for heating and cooling have also been excluded. As a result the remaining database includes about 77,000 observations (approximately 37,000 from 2009 and 40,000 from 2010), each of which is characterized by around 200 variables. 
However, it still seems likely that some reporting mistakes remain, especially concerning the conservation potentials assessed by experts. A closer look at a sample of certification forms reveals that identical measures sometimes are assed differently in terms of saving potential as well as cost. Though this kind of variation may reflect unobserved idiosyncrasies related to the corresponding houses is seems likely that they also are due to unobserved differences between the experts. The same kind of variability among experts may also apply to the cases where they have estimated the use of energy for different purposes.

Tables 1 and 2 give an overview of the data related to our hypotheses and appendix table A1 shows additional data used as control variables when testing them. 
Table 1

Building and energy attributes - median, mean and standard deviation (St.D)

\begin{tabular}{|c|c|c|c|c|}
\hline Variable & $\mathrm{N}$ & Median & Mean & St.D \\
\hline \multicolumn{5}{|l|}{ Energy consumption } \\
\hline Total energy consumption, kWh per year........................ & 76770 & 21712,50 & 23709,11 & 9707,17 \\
\hline Total energy consumption, kWh per square meter and year...... & 76770 & 140,43 & 148,42 & 54,76 \\
\hline Energy for heating \& cooling $\mathrm{kWh}$ per year....................... & 76770 & 16562,00 & 18517,03 & 9036,92 \\
\hline Energy for heating \& cooling kWh per sqm and year............. & 76770 & 107,00 & 115,46 & 50,87 \\
\hline 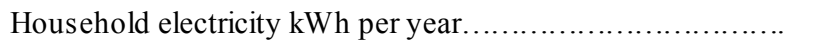 & 76770 & 5000,00 & 5192,09 & 1988,61 \\
\hline Household electricity $\mathrm{kWh}$ per square meter and year............. & 76770 & 31,51 & 32,96 & 12,74 \\
\hline \multicolumn{5}{|l|}{ Experts' assessment } \\
\hline Sum of energy reduction, $\mathrm{kWh}$ per year............. & 75925 & 1100,00 & 3575,31 & 5692,82 \\
\hline Cost of energy reduction, EUR per kWh........................... & 51298 & 0,05 & 0,06 & 0,08 \\
\hline \multicolumn{5}{|l|}{ Type of housing (\%) } \\
\hline 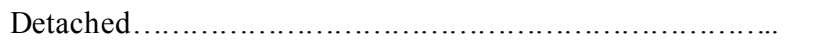 & 60099 & 78,52 & & \\
\hline Semi-detached.................. & 8894 & 11,62 & & \\
\hline Duplex............ & 7538 & 9,85 & & \\
\hline \multicolumn{5}{|l|}{ Period of construction (\%) } \\
\hline 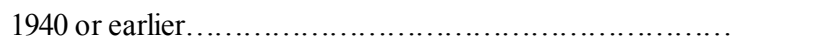 & 16262 & 21,18 & & \\
\hline 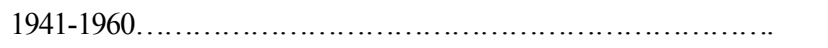 & 12628 & 16,45 & & \\
\hline $1961-1970 \ldots \ldots \ldots \ldots \ldots \ldots \ldots$ & 13257 & 17,27 & & \\
\hline $1971-1980 \ldots \ldots \ldots$. & 19506 & 25,41 & & \\
\hline $1981-1990 \ldots \ldots \ldots \ldots \ldots \ldots \ldots$ & 7640 & 9,95 & & \\
\hline $1991-2000 \ldots \ldots \ldots \ldots \ldots \ldots$ & 3470 & 4,52 & & \\
\hline 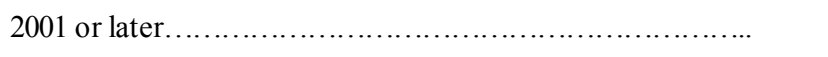 & 4007 & 5,22 & & \\
\hline \multicolumn{5}{|l|}{ Other housing attributes } \\
\hline Heated floor area, sqm............. & 76770 & 157,00 & 166,91 & 57,32 \\
\hline New facade 2003 or later $(\%) \ldots \ldots \ldots \ldots \ldots \ldots \ldots \ldots \ldots \ldots$ & 785 & 1,03 & & \\
\hline 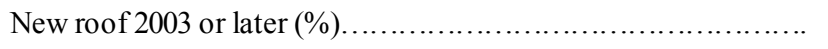 & 2078 & 2,72 & & \\
\hline \multicolumn{5}{|l|}{ Type of windows $(\%)$} \\
\hline 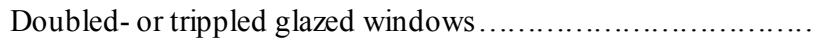 & 74014 & 97 & & \\
\hline 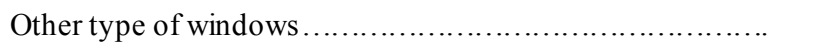 & 2290 & 3 & & \\
\hline \multicolumn{5}{|l|}{ Sources of energy*) $(\%)$} \\
\hline Only electricity ......................... & 15091 & 19,66 & & \\
\hline Only district heating.................... & 9689 & 12,62 & & \\
\hline Only ground sourced heat pump.............. & 6808 & 8,87 & & \\
\hline 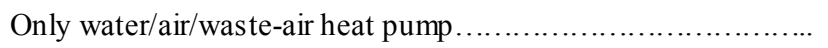 & 5752 & 7,49 & & \\
\hline Only biofuels ..................................... & 3437 & 4,48 & & \\
\hline 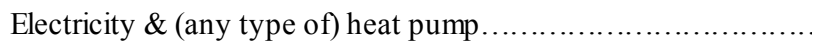 & 11398 & 14,85 & & \\
\hline 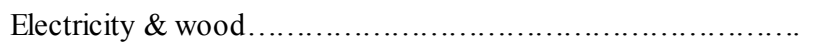 & 6161 & 8,03 & & \\
\hline Electricity, biofuels and (any type of) heatpump................... & 4568 & 5,95 & & \\
\hline 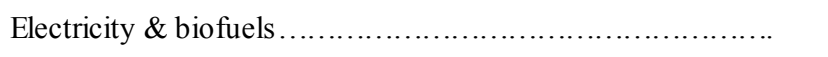 & 1398 & 1,82 & & \\
\hline 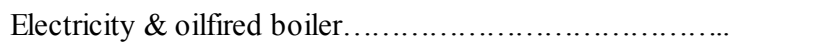 & 895 & 1,17 & & \\
\hline Ohter type of energy or energy combination....................... & 11573 & 15,07 & & \\
\hline 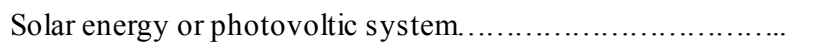 & 520 & 0,68 & & \\
\hline Average number of frost days per year......................... & 76569 & 92,60 & 107,89 & 34,90 \\
\hline
\end{tabular}


As shown in table 1, the average total energy consumption is around $23,700 \mathrm{kWh}$ per year or $148 \mathrm{kWh}$ per square meter. The average use of energy for heating and cooling purposes amounts to about $18,500 \mathrm{kWh}$ per year or $115 \mathrm{kWh}$ per square meter. The energy used for heating and cooling in our data can be compared to the maximum energy use allowed for new homes is $102 \mathrm{kWh} / \mathrm{sqm}$ in Northern Sweden, $82 \mathrm{kWh} / \mathrm{sqm}$ in the middle parts of the country and $62 \mathrm{kWh} / \mathrm{sqm}$ in Southern Sweden ${ }^{4}$. Our data for the corresponding climate zones is provided in figure 1 . As expected, the average energy use for heating and cooling is considerably higher than the recommendations for new homes. In Southern Sweden, where about 80 percent the single family homes in our database are located, the average use of energy is $112 \mathrm{kWh}$, which is 65 percent higher than the recommendation ${ }^{5}$.

\section{Figure 1}

Average energy consumption in $\mathrm{kWh}$ per square meter and year for different purposes and in different climate zones.

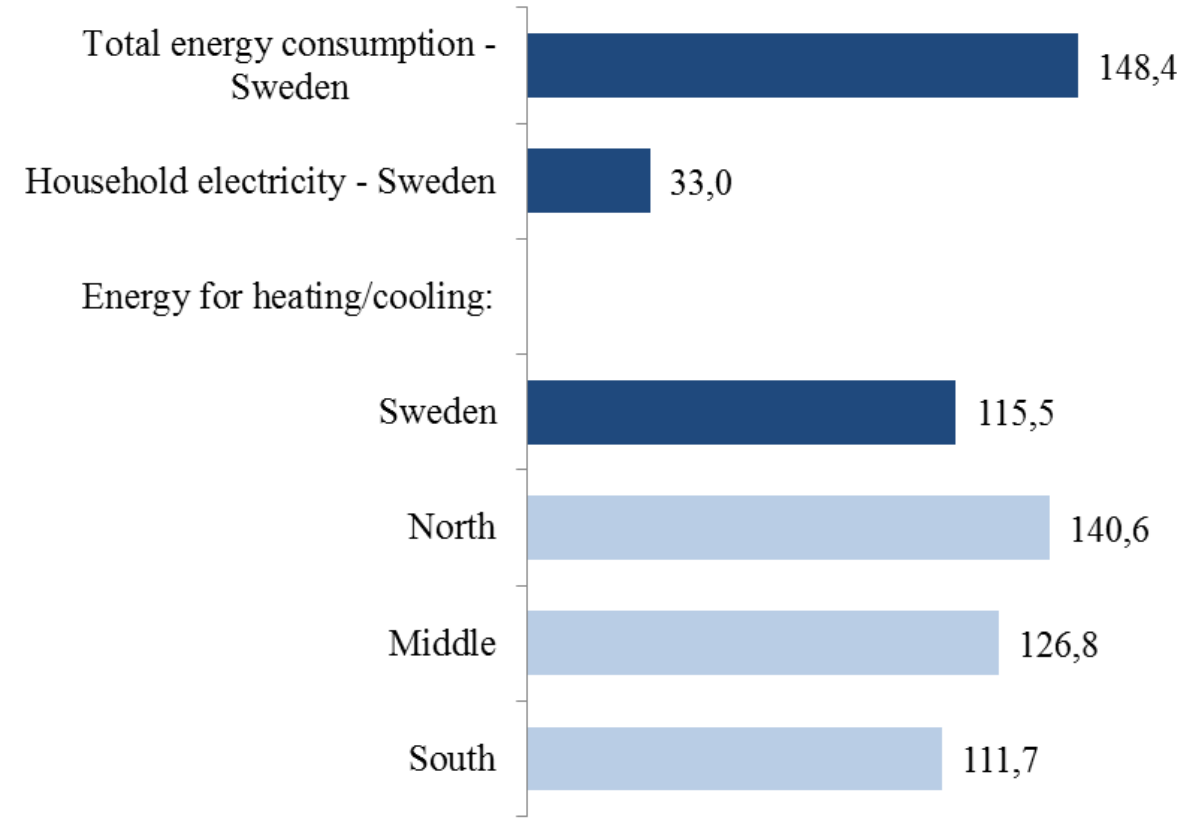

\footnotetext{
${ }^{4}$ The regulations, issued by the Swedish National Board of Housing, Building and Planning, are different for new homes heated by electricity and by other sources of energy. We have calculated a weighted average for each climate zone by using as weights the number of houses in our data base using only electricity respectively other sources of energy.

${ }^{5}$ Though the averages are based on 76000 transactions constituting approximately 4 percent of all single-family houses in Sweden it should be underlined that they do not correspond to a random sample of single family homes.
} 
The average number of frost days ranges from about 60 in the southern Sweden to about 260 in the northern part of the country and it also varies substantially within the three climate zones. In order to capture this variation we will use the average number of frost days per year in each municipality as an indicator of the outdoor temperature ${ }^{6}$.

According to the experts, the energy consumption will be reduced with 3,575 $\mathrm{kWh}$ per house and year, would their suggested saving measures be implemented. Expressed in another way, 15 percent of the total energy consumption can be saved by applying fairly simple and cost efficient measures.

Table 1 also shows that close to 79 percent of houses are detached buildings, that only 20 percent are constructed after 1980 and that the average dwelling size (heated area) is 167 square meters. The relatively large stock of houses constructed before 1980 may explain the frequent use of heat pumps; some kind of heat pump is installed in more than one of three houses. Electricity is the most common source of energy and different energy sources are often combined; together, the combinations cover about 85 percent of the observations. As a single energy source electric direct heating or water-filled radiators heated by electricity is used in about 20 percent, and district heating in 13 percent of the houses.

Information about the households is provided in table 2, showing that the average household size is 2.30 and the average income (household head) is 66,286 Euro per year ${ }^{7}$. More than a third of the households living in single family houses are single and 41 percent have children. We do not have any data on the households' environmental awareness but following Costa and Kahn [6], [13], we have included two "green" indicators in the database. They suggest that a liberal/environmentalist ideology leads to the purchase of greener durables and that the greater the fraction of liberals in a block group and the greater the fraction of hybrid cars among registered vehicles in the block group, the lower are electricity purchases. The definition of green cars used by Sweden's Central Bureau of Statistics is rather complicated but by and large means cars emitting less than 120 gram carbon dioxide per kilometer driven. According to this definition 5 percent of the households own a green car. Our second green

\footnotetext{
${ }^{6}$ Computed for the years 2004-2008 by means of data from the Swedish Meteorological and Hydrological Institute.

${ }^{7}$ Exchange rate: 1 EUR $=8.5 \mathrm{SEK}$
} 
indicator measures the percentage of the local electorate supporting the Environmentalist party according to the municipal elections in 2010.

Table 2

Household characteristics - median, mean and standard deviation (St.D)

\begin{tabular}{|c|c|c|c|c|}
\hline & & Median & Mean & St.D \\
\hline Household size. & 75978 & 2,00 & 2,30 & 1,30 \\
\hline Age (household head)..... & 75978 & 53,00 & 54,80 & 16,32 \\
\hline Singles $(\%) .$. & 27071 & 35,63 & & \\
\hline Elderly hous eholds (age $>65) \ldots \ldots \ldots$ & 21246 & 27,67 & & \\
\hline Households with children.... & 31649 & 41,23 & & \\
\hline Disposible income (household head), EUR per year.............. & 74250 & 46147,18 & 66285,67 & 57651,60 \\
\hline Non-Swedish ethnic background $(\%)^{*}$. & 12265 & 16,17 & & \\
\hline 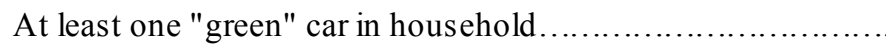 & 3763 & 4,9 & & \\
\hline $\begin{array}{l}\text { Share of votes on the Environmentalist party (MP) - } \\
\text { municipality } \ldots \ldots \ldots \ldots \ldots \ldots \ldots \ldots \ldots \ldots \ldots \ldots \ldots \ldots \ldots \ldots \ldots \ldots \ldots \ldots \ldots \ldots \ldots\end{array}$ & 76770 & 6,00 & 6,38 & 2,72 \\
\hline
\end{tabular}

${ }^{*}$ Foreign-born or Swedish-born with at least one foreign-born parent

\section{Regression Models and Estimations}

Two basic econometric models will be used to test the hypotheses stated in section 2 . The first one, equation (1), relates energy consumption to housing attributes and household characteristics and equation (2) the assessed saving potential to energy consumption and housing attributes.

$\ln E_{i j}=\alpha_{0}+\alpha_{1 j} x_{j}+\alpha_{2 i} h_{i}+\alpha_{3 j} \ln T_{j}+\varepsilon_{i j}$

$\ln S_{\mathrm{ij}}=\beta_{0}+\beta_{1}\left(\ln \mathrm{E}_{\mathrm{ij}}\right)+\beta_{2} \mathrm{x}_{j}+\beta_{3} \ln \mathrm{T}_{j}+\mu_{\mathrm{ij}}$

$\mathrm{E}_{i j}$ denotes energy consumption, measured in $\mathrm{kWh}$ per year, for a household of type $i$ living in a house of type $j, \mathrm{x}_{1 j}$ is a vector of building $j$ 's attributes and $\mathrm{h}_{i}$ a vector of the household $i$ 's characteristics. $\mathrm{T}_{j}$ is an indicator of the climate related to house $j$ and $\varepsilon_{i j}$ is the error term. In line with Brounen et al [3] and to facilitate the interpretation of the coefficients, the dependent variable as well as all continuous explanatory variables have been expressed in logarithms in 
both models ${ }^{8}$. We assume all households to face similar average and marginal energy prices since there is a strong competition between the utility companies. Model (1) has been estimated using both the energy consumption for heating and cooling, the consumption of household electricity and the total energy consumption as dependent variables.

In model (2), $S_{\mathrm{ij}}$ denotes the assessed saving, in $\mathrm{kWh}$ per year, for house $\mathrm{j}$ and $\mu_{\mathrm{ij}}$ the error term. The simple assumption behind the model is that the experts will use the energy-related information they have specified in the certificates. For that reason, the socio-economic characteristics of the residents are not included as explanatory variables. However, knowing that they have transformed the energy consumption data to a year considered normal from a climate perspective, we have included the local number of frost days.

Any two experts may arrive at different assessments of the saving potential even if they are certifying identical houses using the same quantity of energy. In order to test for such a lack of interrater reliability we have included the county (there are 21 counties in Sweden) where a house is located as a dummy variable. The rational for this is that experts operating on the same regional market presumably are more likely to meet and exchange experiences than those operating in different regions.

It should be added that observations with missing values on any of the explanatory variables have been excluded when running the regressions. As a result the number of observations in the regressions ranges between 51,800 and 69,600.

Table 3 presents the results when estimating equation (1). The first two columns show the influence of housing and household attributes on the consumption of energy for heating and cooling and the third column the corresponding impact on the consumption of household electricity. In order to improve readability the coefficients related to the control variables are presented in appendix (table A2). The dependent variable in the first two columns is energy use for heating and cooling during a year having a normal climate. However, it should be mentioned that all estimated coefficients remain almost the same when instead using the nonnormalized quantities as dependent variables. The reason for excluding houses having electricity as their only source of energy is the experts have estimated their use of energy for

\footnotetext{
${ }^{8}$ The transformation implies that the coefficient of a continuous variable gives the percentage change in the dependent variable resulting from a one percent increase of the explanatory variable.
} 
different purposes. The difference when including these houses in the regressions is also negligible.

Since lightening and use of appliances produce heat we have also estimated specifications testing the impact of household electricity consumption on the use of energy for heating and Though it is difficult to disentangle the causal interdependence between the two, we did not find support for such an effect. 
Tabell 3

Energy consumption explained by housing attributes, hous ehold characteris tics, and climate

1) (ln) Energy consumption from heating/cooling, only houses without $100 \%$ direct electricity

2) (ln) Energy consumption from heating/cooling, only houses without $100 \%$ direct electricity

3) (ln) Household electricity, only houses without $100 \%$ direct electricity

\begin{tabular}{|c|c|c|c|}
\hline & $(1)$ & $(2)$ & (3) \\
\hline & Coef. & $\underline{\text { Coef. }}$ & Coef. \\
\hline Construction year 1900 or earlier............. & $0,281^{* * *}$ & $0,282^{* * *}$ & 0,011 \\
\hline Construction year $1901-1920 \ldots$ & $0,280^{* * *}$ & $0,275^{* * *}$ & 0,011 \\
\hline Construction year 1921-1940. & $0,270^{* * *}$ & $0,268^{* * *}$ & 0,008 \\
\hline Construction year $1941-1960 \ldots .$. & $0,239^{* * *}$ & $0,237^{* * *}$ & $-0,023^{* * *}$ \\
\hline Construction year 1961-1970.. & $0,194^{* * *}$ & $0,193^{* * *}$ & $-0,010$ \\
\hline Construction year $1971-1980 \ldots$. & $0,107^{* * *}$ & $0,109^{* * *}$ & $-0,003$ \\
\hline Construction year 1981-1990.... & $0,050^{* * *}$ & $0,053^{* * *}$ & $0,010 *$ \\
\hline Construction year 1991-2000. & $0,058^{* * *}$ & $0,056^{* * *}$ & $0,031^{* * *}$ \\
\hline Duplex house............... & $-0,154^{* * *}$ & $-0,157^{* * *}$ & $-0,040^{* * *}$ \\
\hline Semi-detached house..... & $-0,042^{* * *}$ & $-0,045^{* * *}$ & $-0,005$ \\
\hline (ln) Size of house - heated area.. & $0,600^{* * *}$ & $0,586^{* * *}$ & $0,429^{* * *}$ \\
\hline New roof 2003 or later.............. & $-0,033^{* * *}$ & $-0,033^{* * *}$ & $0,019^{* *}$ \\
\hline New facade 2003 or later.. & $-0,036^{* * *}$ & $-0,035^{* *}$ & 0,015 \\
\hline Simple type of windows.... & $0,026^{* * *}$ & $0,025^{* * *}$ & $-0,028^{* * *}$ \\
\hline Only district heating............. & $-0,198^{* * *}$ & $-0,199^{* * *}$ & $-0,002$ \\
\hline Only ground sourced heat pump............... & $-0,893^{* * *}$ & $-0,888^{* * *}$ & $-0,002$ \\
\hline Only water, air or waste-air sourced heat pump................... & $-0,619^{* * *}$ & $-0,612^{* * *}$ & 0,004 \\
\hline Only chips, pellets, briquettes, other bio-fuels or wood............ & $0,022^{* *}$ & $0,035^{* *}$ & $0,137^{* *}$ \\
\hline $\begin{array}{l}\text { other bio- } \\
\text { fuels....... }\end{array}$ & $0,025^{* *}$ & $0,038^{* * *}$ & $0,056^{* * *}$ \\
\hline Combination of electricity and heat pump (any type)............. & $-0,549^{* * *}$ & $-0,544^{* * *}$ & $0,027^{* *}$ \\
\hline Combination of electricity and wood.............................. & $-0,165^{* * *}$ & $-0,155^{* * *}$ & $0,019^{*}$ \\
\hline Combination of electricity, bio-fuels and heat pump (any type). & $-0,366^{* * *}$ & $-0,359^{* * *}$ & $0,025^{* *}$ \\
\hline Other energy type or combination of energy types................ & $-0,263^{* * *}$ & $-0,270^{* * *}$ & 0,010 \\
\hline 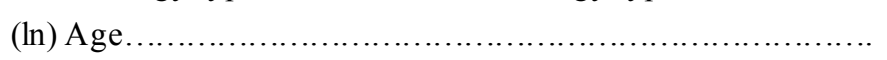 & & $0,022^{* * *}$ & $-0,263^{* * *}$ \\
\hline Household size (number of members)...... & & $0,014^{* * *}$ & $0,072^{* * *}$ \\
\hline 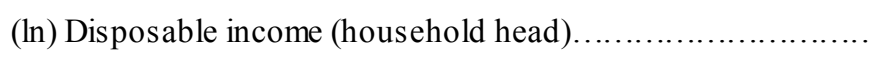 & & $0,010^{* * *}$ & $0,008^{* * *}$ \\
\hline Higher education................... & & $-0,006^{* *}$ & 0,000 \\
\hline At least 1 green car........................... & & $-0,024^{* * *}$ & 0,003 \\
\hline 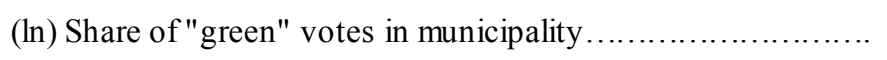 & & $0,008^{* *}$ & $0,060^{* * *}$ \\
\hline (ln) Number of frost days, five year mean per municipality........ & $0,123^{* * *}$ & $0,135^{* * *}$ & $0,027^{* * *}$ \\
\hline 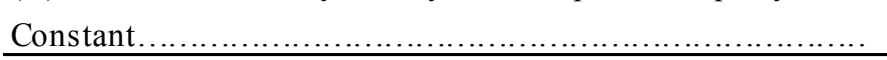 & $6,330^{* * *}$ & $6,098^{* * *}$ & $6,828^{* * *}$ \\
\hline Number of obs............................. & 61113 & 56503 & 56503 \\
\hline Adjusted R2.......... & 0,531 & 0,533 & 0,316 \\
\hline 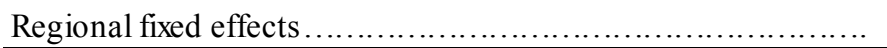 & NO & NO & $\mathrm{NO}$ \\
\hline
\end{tabular}

N.B. All Energy sources are related to energy use for heating and cooling

$* * * p<0.01 \quad * * p<0.05 \quad * p<0.1$ 
The model in column 1, having only housing attributes and climate as explanatory variables, "explains" about 53 percent of the variation in energy consumption for heating and cooling and the variance explained remains practically the same when household characteristics are added, as shown in column 2. Though the energy used for heating and cooling increases significantly with household size, household income and age of the householder, the impact is small. For example, a doubling of the household size from 1 to 2 persons will only increase the energy use for this purpose with 1,4 percent. Households having higher education or green cars consume slightly less energy than other households but the local share of green votes has no significant influence.

The impact related to the housing attributes is considerably stronger. Almost all coefficients are significant and largely stay the same whether household characteristics are included or not. The energy used for heating and cooling increases with the size and age of the house, if it is a detached rather than semi-detached or duplex building and if the windows are of a simple kind. And it is lower for houses having new roofs or new façades and being located where the outdoor temperature is higher. By way of example column 2 shows that the energy use increases with about 5.9 percent, corresponding to 1,093 $\mathrm{kWh}$ per year, when the size of the house increases with ten percent and with 1.4 percent if the number of frost days per year increases with ten percent.

Heat pumps are very strong energy savers according to our results. Compared with a combination of electricity and heat-fired boiler, i e the alternative used as a base in the regression, the two alternatives including heat pumps results in energy savings between 42 and 59 percent according to the second column of table $3 .{ }^{9}$ It should be added that the coefficients only change marginally if houses fully relying on electricity are included in the regression. The result when doing so also reveals that the combination of electricity and heat fired boiler implies a higher energy consumption than an alternative relying on just electricity.

The estimates reported in column 3 also show that household characteristics and housing attributes almost play a reversed role for the consumption of household electricity - only housing size has a noticeable impact while almost all household characteristics are significant. To give some examples, an increase of the heated area with ten percent will increase the

\footnotetext{
${ }^{9}$ The percentual change for dummy variables is calculated according to the following formula: $100 *\left(\mathrm{e}^{\beta}-1\right)$
} 
consumption of household electricity with 4.3 percent, an additional family member will increase it with 7.2 percent and a family with a householder aged 70 will use 26 percent less than families with householders aged 35 .

The fact that use of energy for household purposes declines by age while the use for heating and cooling increases by age may reflect the behavior differences between young and old residents. It is perhaps more common that older residents spend more time in their home and have fewer appliances, e g computers, than younger residents. Neither education nor having a green car matter significantly for the use of household electricity. The other green indicator is significant but has the unexpected sign.

We have also run the three corresponding regression using family types as explanatory variables instead of household size and age of the householder. The results are largely the same regarding the influence of housing related attributes as well as the variance explained.

All in all about 32 percent of the variance in household electricity consumption is explained by our model. The relatively large unexplained variance as well as e $g$ the just noted impact of age, indicate the need to include variables that capture the behavior of the residents as earlier suggested by e g Guerra Santin [9], Costa and Kahn [7].

Turning to energy conservation, the first column of table $\mathbf{4}$ presents the estimated coefficients of equation (2), relating the assessed saving potentials to the total energy consumption, housing attributes and regional location. As a point of reference, the second column shows the results when estimating equation (1) using the total energy consumption as dependent variable. The houses that fully rely electricity, and that were excluded in table 3 , are now included and it should be noticed that electric heating and cooling is now substituted for electricity and oil-fired boiler as the base line heating system. 
Table 4

Saving potential and energy consumption explained by housing attributes, household characteristics, and climate

1) (In) Estimated saving potential (ln), kWh per year

2) (ln) Total energy consumption - both heating/ cooling and household electricity, kWh per year

(ln) Total energy consumption ( $\mathrm{kWh}$ )

Coef.

Coef.

Construction year 1900 or earlier.

$1,590^{* * * *}$

Construction year 1901-1920

$0,344^{* * *}$

Construction year 1921-1940

$0,387^{* * *}$

$0,222^{* * *}$

$0,406^{* * *}$

$0,210^{* * *}$

Construction year 1941-1960

$0,501^{* * *}$

$0,209^{* * *}$

Construction year 1961-1970

$0,495^{* * *}$

$0,183^{* * *}$

Construction year 1971-1980

$0,440^{* * *}$

$0,150^{* * *}$

Construction year 1981-1990

$0,078^{* * *}$

Construction year 1991-2000

$0,210^{* * *}$

$0,044^{* * *}$

Duplexhouse.

$-0,149^{* * *}$

$0,041^{* * *}$

Duplexhouse....

$-0,076^{* * *}$

$-0,157^{* * *}$

Semi-detached house

$-0,401^{* * *}$

$-0,042^{* * *}$

(ln) Size of house - heated area.

$0,560^{* * *}$

New roof 2003 or later

\section{$-0,069$}

$-0,017^{* * * *}$

New facade 2003 or later.

$0,093^{* * *}$

$-0,024^{* *}$

Simple type of windows.

$-0,831^{* * *}$

$0,025^{* * *}$

Only district heating.

$-1,882^{* * *}$

$0,117^{\text {*** }}$

Only ground sourced heat pump.

$-0,410^{* * *}$

$-1,642^{* * *}$

$-0,201^{* * *}$

Only water, air or waste-air sourced heat pump.

$-1,009^{* * *}$

$0,338^{* * *}$

Only chips, pellets, briquettes, other bio-fuels or wood

$-1,533^{* * *}$

$-0,152^{* * *}$

Combination of electricity and heat pump (any type)

$-0,416^{* * *}$

$0,144^{* * *}$

Combination of electricity and wood.

$-0,892^{* * *}$

$0,302^{* * *}$

Combination of electricity and chips, pellets, briquettes or other bio-

Combination of electricity, bio-fuels and heat pump (any type).........

Combination of electricity and oil-fired boiler.

$-1,617^{* * *} \quad-0,014^{* * *}$

$-0,052^{*} \quad 0,268^{* * *}$

Other energy type or combination of energy types.....

$-0,836^{* * *} \quad 0,062^{* * *}$

(ln) Number of frost days, five year mean per municipality

$0,087^{* * *} \quad-0,015^{*}$

(ln) Age......

Household size (number of members).

$-0,035^{* * *}$

$0,027^{* * *}$

$0,004^{* * *}$

(ln) Disposable income (household head)......

$-0,007^{* * *}$

Higher education.

$-0,015^{* * *}$

At least 1 green car.

$0,010^{* * *}$

(ln) Share of "green" votes in municipality.

7,181

Constant............

$-5,827$

69627

Adjusted $\mathrm{R}^{2}$

51801

0,551

Regional fixed effects

0,488

Yes

N.B. All Energy sources are related to energy use for heating and cooling

$* * * p<0.01 \quad * * p<0.05 \quad * p<0.1$ 
The coefficients related to the saving potential reveal that the assessments are significantly influenced by the total energy consumption and most of the housing attributes in the way expected. For example, an increase of the total energy consumption with ten percent will result in a 16 percent higher saving potential and the saving potential for a house constructed between 1941 and 1980 is 55-65 percent higher that for houses constructed later year 2000. With one exception, heated area, the housing attributes seem to contribute in line with our hypotheses A possible reason for the negative impact of a larger heated area might be that the experts considers energy use per square meter when making their assessments rather than considering energy use and size separately. Another possibility is that there are fewer costefficient saving measures that can be implemented in houses having a large rather than a small heated area. It is also noteworthy that the saving potential is higher in houses using only electricity than in houses having all other kinds of heating and cooling system.

As seen when comparing with column 2, most of the explanatory variables influence the saving potentials and the total use of energy in the same direction. The area heated, is as already mentioned, the only exception. However the comparison also reveals that houses constructed in any 10-year period between 1970 and 2000 contribute considerably more to the assessed saving potential than to the use of energy. For example the assessed saving for a house constructed 1981-1990 is 40 percent higher than for a house constructed after 2000 while the corresponding difference in using energy is 5 percent.

The results concerning regional location indicate that interrater reliability problems can not be ruled out. Compared to the Stockholm County, which is used as a norm, 18 other counties have significantly lower assessed saving potentials - the assessments for Gotland are for example 27 percent lower than those for Stockholm while Gotland's positive impact on the energy consumption is 8 percent. Though other unobserved factors may influence the estimates, it still seems worthwhile to have a closer look at this quality aspect of the expert assessments. 


\section{Summary and Conclusions}

This paper deals with residential energy consumption and conservation and rests upon a unique data base. The information provided by the Swedish energy performance certificates for single family homes is the cornerstone of the data base. Each home is described in terms of energy use and a large number of attributes related to the building and the energy system and by an assessment of the energy conservation potential made by the expert issuing the certificate. We have matched this data base with two other sets of data - one with socioeconomic information about the families living in the homes and one with additional data on physical attributes of the buildings and information about their neighborhoods. After excluding certificates with missing or inconsistent information the resulting database, includes around 77,000 individual observations. By means of regression analysis this data base is used to analyze the influence of a large number of housing attributes and household characteristics on the use of energy as well as on the assessed potential for energy conservation.

In line with earlier findings, our results show that household characteristics such as size of the family and age of the householder have a significant influence on the energy use and hence should be included in any study trying to explain the variance of energy use among singlefamily houses. They also show that while the quantitative impact of physical attributes are much more important than the socio-economic characteristics when it comes to the energy use for heating and cooling, it is the other way around when considering the energy use for lightening and appliances. By way of example, an increase of the housing area by ten percent will increase the use of energy for heating with 6 percent and the consumption of household electricity with 4 percent. On the other hand, an additional family member will increase the energy used for heating and cooling with 1.4 percent but the use of household electricity with 7.2 percent.

The results also demonstrate that the kind of energy system used has a strong influence on the energy performance. Houses equipped with heat pumps, and especially ground-sourced ones, use considerably less energy - when compared with identical houses using a combination of oil-fired boiler and electricity, the energy consumption for heating and cooling is almost 60 percent lower. The climate is, of course another very important factor.

The average assessed conservation potential is 3,575 $\mathrm{kWh}$ per house and year, which corresponds to 15 percent of the total energy yearly used by the average house. Considering 
that the assessments are based upon cost-efficient energy saving measures, this conservation potential seems rather impressive. Using regression analysis, our results show that about 49 percent of the variance in assessed savings is can be explained by the total use of energy, the housing attributes and the local outdoor temperature. For example, an increase of the total energy consumption with 10 percent will result in a 16 percent higher conservation potential.

Our analysis of the conservation potentials also shows that the assessments differ across counties in a way that cannot be explained by our data and hence might indicate a lack of interrater reliability among the certification experts. Additionally, a comparison of the impact of the housing attributes on the assessments and the total energy consumption indicates that the experts might have focused to much on the simple indicator energy consumption per unit of heated area rather than considering all housing attributes separately when making their assessment.

Several policy conclusions can be drawn form our result. One is that the government agency responsible for the energy performance certificates should take further steps to improve their quality. Each certificate should be checked concerning consistency between the different data items included and they should be compared concerning interrater reliability among experts from the same firms as well as between firms. Since the socio-economic characteristics of the residents play a significant role the responsible agency should also consider adding some information about the households on future certificates.

As for research needs, this paper indicates the possibility to gain new knowledge about residential energy use and conservation by using energy performance certificates and especially by combining the data on measured energy consumption with saving assessments made by experts. By adding certificates from later years than those included here more could be found out about the robustness of our findings and it would also be possible to analyze to what extent the advice on energy saving measures have been implemented and the assessed conservation potentials realized. 


\section{References}

[1] Ayres I., Raseman S. and Shih A. (2009) Evidence from two large field experiments that peer comparison feedback can reduce residential energy usage. NBER Working Paper 15386

[2] Broin E., Mata É., Göransson A. and Johnsson F. (2013) The effect of improved efficiency on energy savings in EU-27 buildings. Energy 57 (2013) 134-148.

[3] Brounen D., Kok N. and Quigley J.M. (2012) - Residential energy use and conservation: Economics and demographics, European Economic Review 56, 2012, 931-945, Available online: http://elsa.berkeley.edu/ quigley/papers.html

[4] Brounen D., Kok N. and Quigley J. M. (2013) Energy literacy, awareness and conservation behavior of residential households. Journal of energy Economics, 38, 42-50

[5] Caldera M., Corgnati S. P. and Filippi M. (2008) Energy demand for space heating through a statistical approach: application to residential buildings. Journal of Energy and Buildings, 40, 1972-1983

[6] Costa D.L. \& Kahn M.E. (2009) Towards a Greener California: An Analysis of Household Variation in Residential Electricity Purchases. UCLA and NBER 2009

http://urbanpolicy.berkeley.edu/greenbuilding/costakahn_presentation.pdf

[7] Costa D.L. \& Kahn M.E. (2011) Electricity Consumption and Durable Housing:

Understanding Cohort Effects, American Economic Review: Papers \& Proceedings 2011, 101:3, pp 88-92

[8] Ek K and Söderholm P (2010) The devil is in the details: Household electricity saving behavior and the role of information, Energy Policy 38, 1578-1587

[9] Guerra Santin O., Itard L. \& Visscher H. (2009) The effect of occupancy and building characteristics on energy use for space and water heating in Duch residential stock. Energy and Buildings 41 (2009) 1223-1232

[10] Guerra Satin O. and Itard L. (2010) Occupants' behavior: determinants and effects on residential heating consumption. Building, Research \& Information, 38:3, 318-338.

[11] Guerra Santin O. (2011) Behavioural Patterns and User Profiles related to energy consumption for heating. Energy and Buildings 43 (2011) 2662-2672.

[12] Haas R., Auer H. and Biermayr P. (1998) The impact of consumer behavior on residential energy demand for space heating. Energy and Buildings 27 (1998) 195-205.

[13] Kahn M.E. (2007) Do greens drive hummers or hybrids? Environmental ideology as a determinant of consumer choice Journal of Environmental Economics and Management, (2007), doi:10.1016/j.jeem.2007.05.001

[14] Kavgic M., Mavrogianni A., Mumovic D., Summerfield A., Stevanovic Z. and DjurovicPetrovic M. (2010) A review of bottom-up building stock models for energy consumption in the residential sector. Building and Environment, 45, 1683-1697 
[15] Kelly S. (2011) Do homes that are more energy efficient consume less energy?: A structural equation model of the English residential sector. Energy 36 (2011) 5610 -5620.

[16] Larsen B. M. and Nesbakken R. (2004) Household electricity end-use consumption: results from econometric and engineering models. Energy Economics 26, 179-200

[17] Mansouri I., Newborough M and Probert D. (1996) Energy consumption in UK Households: Impact of Domestic Electrical Appliances, Journal of Applied Energy, Vol 54, No. 3, 211-285

[18] Mata E., Kalagasidis A. S., Johnsson F. (2013) Energy usage and technical potential for energy saving measures in the Swedish residential building stock, Energy Policy, 55, 404-414

[19] Sexton and Sexton (2012) Conspicuous conservation: The Prius halo and willingness to pay for environmental bona fides. Journal of Environmental Economics and Management, 2014, vol. 67, issue 3, 303-317

[20] Swan L. S. And Ugursal V. I. (2009) Modeling of end-use energy consumption in the residential sector: A review of modeling techniques. Renewable and Sustainable Energy Reviews, 13, 1819-1835

[21] Zoric J and Hrovatin N (2012) Household willingness to pay for green electricity in Slovenia. Energy Policy 47, 180-87

[22] Boverket (2014) Vägledning till formulär för energideklaration. Version 2.2. www.boverket.se 


\section{APPENDIX}

Table A1

Housing attributes used as control variables - percent (\%)

\begin{tabular}{|c|c|c|}
\hline Variable & $\mathrm{N}$ & $\%$ \\
\hline \multicolumn{3}{|l|}{ Type of ventilation (\%) } \\
\hline Ventilation type natural draft. & 48052 & 62,59 \\
\hline Ventilation type F; waste air....... & 12084 & 15,74 \\
\hline Ventilation type FT; both waste and supply air.............. & 1716 & 2,24 \\
\hline Ventilation type FTX; waste air used for heating supply & 6040 & 7,87 \\
\hline Ventilation type w recycling.......... & 3975 & 5,18 \\
\hline \multicolumn{3}{|l|}{ Other housing attributes (\%) } \\
\hline Two or more bathrooms (\%).. & 23997 & 31,26 \\
\hline New kitchen equipment 2003 or later (\%).. & 4007 & 5,25 \\
\hline \multicolumn{3}{|l|}{$\underline{\operatorname{Year}(\%)}$} \\
\hline Year 2009 & 37112 & 48,34 \\
\hline ear 2010. & 39658 & 5 \\
\hline
\end{tabular}

\section{Tabell A2}

\section{Energy consumption explained by control variables}

1) (In) Energy consumption from heating/cooling, only houses without $100 \%$ direct electricity

2) (ln) Energy consumption from heating/cooling, only houses without $100 \%$ direct electricity

3) (In) Household electricity, only houses without $100 \%$ direct electricity

\begin{tabular}{|c|c|c|c|}
\hline & (1) & (2) & (3) \\
\hline & $\underline{\text { Coef. }}$ & $\underline{\text { Coef. }}$ & $\underline{\text { Coef. }}$ \\
\hline 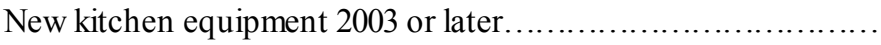 & 0,001 & 0,002 & 0,033 \\
\hline Two or more bath rooms.... & $0,015^{* * *}$ & $0,013^{* * *}$ & 0,030 \\
\hline 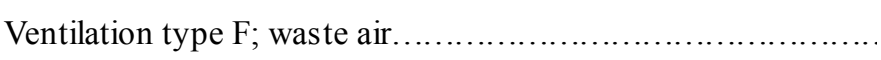 & $0,010^{* *}$ & $0,008^{*}$ & 0,056 \\
\hline 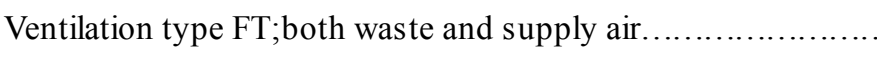 & 0,004 & $-0,001$ & 0,087 \\
\hline Ventilation type FTX; waste air used for heating supply air...... & 0,004 & 0,002 & 0,062 \\
\hline Ventilation type with recycling..... & $0,037^{* * *}$ & $0,0322^{* * *}$ & 0,025 \\
\hline Foreign background... & & 0,002 & 0,009 \\
\hline Constant. & $6,330^{* * *}$ & $6,098^{* * *}$ & 6,828 \\
\hline Number of obs...... & 61113 & 56503 & 56503 \\
\hline 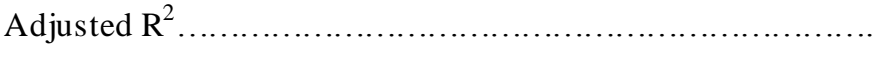 & 0,531 & 0,533 & 0,316 \\
\hline 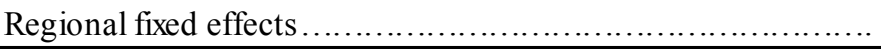 & NO & NO & NO \\
\hline
\end{tabular}


Table A3

\section{Saving potential and energy consumption explained by control variables}

1) (ln) Estimated saving potential (ln), kWh per year

2) (ln) Total energy consumption - both heating/ cooling and household electricity, kWh per year

\begin{tabular}{|c|c|c|c|c|}
\hline & & & \multicolumn{2}{|c|}{ procentual changes } \\
\hline & $(1)$ & $(2)$ & 1) & 2) \\
\hline & Coef. & & & \\
\hline New kitchen equipment 2003 or later...... & $-0,070^{* * *}$ & $0,014^{* * *}$ & & \\
\hline Two or more bath rooms.... & $-0,044^{* * *}$ & $0,009^{* * *}$ & & \\
\hline Ventilation type $\mathrm{F}$; waste air.............. & $-0,173^{* * *}$ & $0,012^{* * *}$ & & \\
\hline Ventilation type FT; both waste and supply air................. & $-0,236^{* * *}$ & $0,019^{* * *}$ & & \\
\hline Ventilation type FTX; waste air used for heating supply air.... & $-0,165^{* * *}$ & $0,010^{* *}$ & & \\
\hline Ventilation type with recycling........... & $-0,021$ & $0,017^{* * *}$ & & \\
\hline Foreign background..... & & $-0,002$ & & \\
\hline Region - Blekinge.. & $-0,145$ & $-0,163$ & $-13,48$ & $-15,00$ \\
\hline Region - Dalarna.......... & $-0,121$ & 0,007 & $-11,41$ & 0,70 \\
\hline Region - Gävleborg....... & $-0,181$ & $-0,015$ & $-16,57$ & $-1,49$ \\
\hline Region - Gotland....... & $-0,313$ & $-0,081$ & $-26,90$ & $-7,80$ \\
\hline Region - Halland..... & $-0,214$ & $-0,078$ & $-19,24$ & $-7,46$ \\
\hline Region - Jämtland......... & $-0,039$ & 0,083 & $-3,78$ & 8,67 \\
\hline Region - Jönköping..... & $-0,141$ & $-0,059$ & $-13,12$ & $-5,73$ \\
\hline Region - Kalmar.. & $-0,122$ & $-0,115$ & $-11,49$ & $-10,83$ \\
\hline Region - Kronoberg..... & 0,014 & $-0,109$ & 1,41 & $-10,33$ \\
\hline Region - Norrbotten........ & $-0,190$ & 0,154 & $-17,34$ & 16,70 \\
\hline Region - Örebro............ & $-0,238$ & $-0,048$ & $-21,19$ & $-4,73$ \\
\hline Region - Östergötland.... & $-0,143$ & $-0,070$ & $-13,31$ & $-6,72$ \\
\hline Region - Skåne............... & $-0,045$ & $-0,056$ & $-4,38$ & $-5,44$ \\
\hline Region - Södermanland......... & $-0,115$ & $-0,065$ & $-10,87$ & $-6,30$ \\
\hline Region - Uppsala.......... & $-0,154$ & $-0,035$ & $-14,25$ & $-3,47$ \\
\hline Region - Värmland..... & $-0,148$ & $-0,029$ & $-13,77$ & $-2,85$ \\
\hline Region - Västmanland..... & $-0,232$ & 0,061 & $-20,73$ & 6,26 \\
\hline Region - Västerbotten..... & $-0,204$ & 0,106 & $-18,43$ & 11,18 \\
\hline Region - Västergötland... & $-0,052$ & $-0,077$ & $-5,09$ & $-7,41$ \\
\hline Region - Västernorrland. & $-0,151$ & 0,047 & $-14,04$ & 4,81 \\
\hline 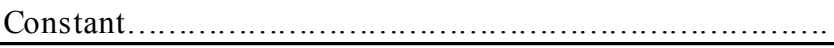 & $-5,827$ & 7,181 & & \\
\hline Number of obs & 51801 & 69627 & & \\
\hline Adjusted $\mathrm{R}^{2}$ & 0,488 & 0,551 & & \\
\hline Regional fixed effects & Yes & Yes & & \\
\hline
\end{tabular}

Significance levels: $* * *(p<0.01), * *(p<0.05), *(p<0.1)$ 